\title{
Adolescent low back pain among secondary school students in Ibadan, Nigeria
}

Babatunde O. A. Adegoke, Adesola C. Odole, Adebayo A. Adeyinka

Department of Physiotherapy, College of Medicine, University of Ibadan, Ibadan, Nigeria

\begin{abstract}
Background: Adolescent low back pain (ALBP) can be considered a signal or precursor of a serious organic disease or telltale sign of future incidence of low back pain in adulthood. Published articles on ALBP in Nigeria are not readily available. Objectives: The study's objectives were to investigate the prevalence of Adolescent Low Back Pain (ALBP) among secondary school students in Ibadan, Nigeria and the prevalence's association with some socio-demographic variables.

Methods: Participants were adolescent students from 15 secondary schools in Ibadan. Data was collected using a respondent-administered, validated questionnaire on low back pain in adolescents. Participants (Female: 298; Male: 273) aged 14.23 \pm 2.27 years (range 10-19) were recruited through multi-stage random sampling. Five hundred and seventy-one (83.97\%) of the 680 copies of the questionnaire administered were returned. Data was analysed using mean, standard deviation, frequency, percentages, and Chi-square test with alpha level at 0.05 .

Result: Lifetime, twelve-month, one-month and point prevalence rates of ALBP were 58.0\%, 43.8\%, 25.6\% and 14.7\% respectively. Age at first experience of ALBP was $11.86 \pm 2.36$ years. Gender was not significantly associated with any rate $(p \geq 0.317)$. Age $(p \leq 0.043)$ and engagement in commercial activities $(p \leq 0.025)$ were significantly associated with all period prevalence rates while injury to the back was significantly associated with all period prevalence rates except point prevalence $(\mathrm{p}=0.087)$.

Conclusion: Adolescent low back pain is common among secondary school students in Ibadan and its prevalence is significantly associated with age and engagement in commercial activities, but not with gender.
\end{abstract}

Key Words: Adolescent, low back pain, school children

DOI: http://dx.doi.org/10.4314/ahs.v15i2.16

\section{Background}

Low back pain (LBP) is pain or discomfort in the lumbo-sacral region of the back. It is referred to as Adolescent Low Back Pain (ALBP) when it occurs in individuals between the ages of 10 and 19 years ${ }^{1}$. The presence of LBP in adolescence is seen by some as a signal for or a precursor of a serious organic disease, while others see it as a tell-tale sign for future incidence of low back pain in adulthood ${ }^{2,3}$. A scientific interest in ALBP is of importance as it is believed by some to be unusual and rare for that age group ${ }^{1,4,5}$.

\section{Corresponding author:}

Babatunde O. A. Adegoke,

Department of Physiotherapy,

College of Medicine,

University of Ibadan,

Ibadan, Nigeria.

E-mail: badegoke@comui.edu.ng,

babatundeadegoke@yahoo.com
In the industrialized world, it has been estimated that about $80 \%$ of the general population will report low back pain at one point or the other in their life $e^{5,6,7}$ LBP has been described as a common phenomenon that affects public health ${ }^{6,8}$ and it is now being increasingly recognized that LBP in childhood and adolescence is becoming almost as common a complaint as that observed in adults ${ }^{8,9,10}$. It has also been described as a public health problem in children, although as a less globally recognized problem ${ }^{5,8}$. Probably based on the premise that LBP is unique to adults ${ }^{4}$ and rare in adolescents, the volume of research on ALBP had in the past been small and hence the limited data on the prevalence of LBP in adolescents ${ }^{1,5}$. Since the 1980s, there has been an increasing appreciation of the prevalence of ALBP in the community, and in recent times there has been a significant increase in the number of studies on $\mathrm{it}^{1}$. This shift in awareness appears to have resulted from a series of international epidemiological studies which identified a significant prevalence of reported spinal pain in otherwise "healthy" adolescents ${ }^{1,4}$. 
Recent epidemiologic data has suggested a relatively high prevalence of LBP during school age?. However, estimates of LBP prevalence in children and adolescents reported in studies vary widely between studies depending on the age of study participants, and meth odological differences - particularly in terms of LBP definition ${ }^{1,7}$. Prevalence rates of LBP among children and adolescents of various ages have been reported in terms of period prevalence; one-month prevalence, 12-month prevalence and lifetime prevalence being the common period prevalence rates reported by authors $5,6,8,11,12$. Jeffries et $a^{13}$, in a systematic review, reported that the prevalence of low back pain (LBP) during school years ranges from 7\% to $70 \%$ in developed countries, depending on the definition of pain and the study design and that the lifetime prevalence increases with age, reaching $67.9 \%$ to $74 \%$ by late adolescence. Ayanniyi et $\mathrm{al}^{11}$ reported a $25 \%$ lifetime prevalence of back pain among school-age adolescents in Nigeria ${ }^{11}$ but failed to report other period prevalence rates. Louw et $\mathrm{al}^{14}$ reported the mean LBP point prevalence, 12-month prevalence and lifetime prevalence among African adolescents to be $12 \%, 33 \%$ and $36 \%$ respectively.

A large percentage of the data available on ALBP is the epidemiology of ALBP in Africa exist. There is a dearth of data on the prevalence of ALBP in Africa generally $y^{13}$ and specifically in Nigeria ${ }^{11}$. The only article on LBP among adolescents in Nigeria that is available for referencing ${ }^{11}$ is limited in its utility in that only lifetime prevalence of ALBP was reported as part of a general investigation of back pain among adolescents, a standardized questionnaire on low back pain was not used and there was no working definition for low back pain or ALBP. This study was hence designed to investigate the prevalence of ALBP among secondary school students in Ibadan north local government area of Oyo state, Nigeria.

\section{Methods}

\section{Participants}

Participants were secondary school students of ages 10by visual inspection by one of the authors at the point of questionnaire administration. The visual inspection comprised essentially of an assessment of participants posture for anterior/posterior and lateral symmetries to rule out excessive lumbar or cervical lordosis, increased thoracic kyphosis and scoliosis. from Europe and America, though a few studies on 19 years with no obvious spinal deformity as revealed

velopment, using a checklist for developing a questionnaire by Boynton and Greenhalgh ${ }^{18}$. The questionnaire was also pilot-tested among 72 students for its comprehensibility and clarity and among 22 students for its reliability. Its valid response rate was $95.8 \%$, while Cronbach's alpha for its test-retest reliability ranged from 0.49-0.99. The students involved in the questionnaire's comprehension and reliability tests were excluded from the main study to forestall the effect of testing/learning on the study's outcome. The questionnaire was used to collect data on lifetime, 12-month, one-month and point prevalence of adolescent low back pain among the participants. It was also used to identify some contributory factors to low back pain.

Respondents were asked whether they had experienced LBP at their lower back region as was depicted by a diagram on the questionnaire. LBP was defined as pain or discomfort felt in the lumbo-sacral region of the back that is not related to menstrual periods or feveris illness such as the 'common cold or flu'. The data from

\section{Procedure}

The study's protocol was approved by the University of Ibadan/University College Hospital Research Ethics Committee while participants gave informed consent/ assent before being recruited into the study. Prior to the administration of the questionnaires, a letter of introduction explaining the purpose of the study and assuring participants and their parents of the confidentiality of the data obtained was sent to parents of participants younger than 16 years to obtain their consent for their children's participation. A total of 680 copies of a respondent-administered, validated questionnaire were distributed among participants, but only 571 copies $(83.97 \%)$ were returned. Copies of the questionnaire were distributed to the students by hand while one of the researchers waited to collect them on completion.

The questionnaire (Appendix 1) for this study was compiled based on questions from previously published surveys $5,6,11,16,17$, but adapted and validated for use among Nigerian adolescents. The questionnaire had two sections and contained 22 questions. Section A of the questionnaire sought information on the demographic characteristics of sex, age, height and weight of parto ascertain the presence and history of low back pain. The questionnaire was assessed for face and content validity by clinical physiotherapists and academic physiotherapists who are knowledgeable in questionnaire de-
The period prevalence rates among participants are presented in Table 2. Three hundred and thirty-one $(58.0 \%)$ participants reported ever experiencing low back pain in their life time, while $250(43.8 \%)$ and $146(25.6 \%)$ reported to have experienced pain in the lower part of their back (as depicted in the diagram on the question-

this study were analysed using SPSS version 15. Statistical analyses were conducted using descriptive statistics of mean, standard deviation, frequency and percentages and inferential statistic of Chi-square, with level of significance $(\alpha)$ set at 0.05

\section{Results}

Six hundred and eighty (680) copies of the questionnaire were distributed, but only $571(83.97 \%)$ was returned and analysed. Participants (298 females (52.2\%); 273 males $(47.8 \%)$ ) were aged $14.23 \pm 2.27$ years (range $=$ 10-19 years). The participants' mean weight and height were $44.68 \pm 10.46 \mathrm{~kg}$ and $1.55 \pm 0.01 \mathrm{~m}$ respectively (Table 1). Male participants $(14.29 \pm 2.37$ years) were significantly older than female participants (14.18 \pm 2.16 years). Boys were significantly taller $(p=0.000)$ but weighed significantly lesser than the girls $(p=0.027)$ The BMI of boys and girls were not sionificantly different while participants first experienced low back pain at $11.86 \pm 2.36$ years.

Table 1: Participants' socio-demographic characteristics

\begin{tabular}{|c|c|c|c|c|c|}
\hline Variable & $\begin{array}{c}\text { Boys } \\
(\mathrm{n}=273)\end{array}$ & $\begin{array}{l}\text { Girls } \\
(n=298)\end{array}$ & $\mathbf{p}$ & $\begin{array}{c}\text { All } \\
(\mathrm{n}=\mathbf{5 7 1})\end{array}$ & Range \\
\hline Age (yrs) & $14.29 \pm 2.37$ & $14.18 \pm 2.16$ & 0.022 & $14.23 \pm 2.27$ & $10-19$ \\
\hline Height (m) & $1.55 \pm 0.12$ & $1.54 \pm 0.09$ & 0.000 & $1.55 \pm 0.10$ & $1.27-1.83$ \\
\hline Weight (kg) & $44.13 \pm 11.01$ & $45.18 \pm 9.92$ & 0.027 & $44.68 \pm 10.46$ & $24-79$ \\
\hline BMI $\left(\mathrm{kg} / \mathrm{m}^{2}\right)$ & $18.07 \pm 2.61$ & $18.75 \pm 2.90$ & 0.068 & $18.43 \pm 2.79$ & $11.71-28.16$ \\
\hline $\begin{array}{l}\text { Age at first pain } \\
\text { experience (yrs) }\end{array}$ & $11.56 \pm 2.61$ & $12.13 \pm 2.07$ & & $11.86 \pm 2.36$ & $5-18$ \\
\hline \multicolumn{3}{|c|}{ Duration of last episode } & \multicolumn{3}{|c|}{$\begin{array}{l}<\text { One day }-54.5 \% \\
<\text { One week }-31.2 \% \\
<\text { One month }-7.9 \% \\
<\text { Three months- } 3.0 \% \\
>\text { Three months }-3.3 \%\end{array}$} \\
\hline
\end{tabular}

naire) in the twelve months and one month preceding the study respectively. Further, 84 (14.7\%) participants reported the presence of pain in the lower part of their back as at the time of the study (point prevalence). Thus the lifetime, twelve-month, one-month and point prevalence of LBP were found to be $58.0 \%, 43.8 \%, 25.6 \%$ and $14.7 \%$ respectively. 
Table 2: Period prevalence rates and characteristics of adolescent low back pain among

\begin{tabular}{|c|c|c|c|c|c|}
\hline Variable & $\begin{array}{c}\text { Boys } \\
(\mathrm{n}=273)\end{array}$ & & $\begin{array}{c}\text { Girls } \\
(\mathrm{n}=\mathbf{2 9 8})\end{array}$ & $\mathbf{p}$ & $\begin{array}{l}\text { All } \\
(\mathrm{n}=571)\end{array}$ \\
\hline \multicolumn{6}{|l|}{ Period prevalence (n / \%) } \\
\hline Lifetime & $160 / 58.6$ & & $171 / 57.4$ & 0.767 & $331 / 58.0$ \\
\hline 12-month & $120 / 44.0$ & & $130 / 43.6$ & 0.936 & $250 / 43.8$ \\
\hline One-month & $68 / 24.9$ & & $78 / 26.8$ & 0.729 & $146 / 25.6$ \\
\hline Point & $36 / 13.2$ & & $48 / 16.2$ & 0.317 & $84 / 14.7$ \\
\hline Recurrence & $130 / 43.6$ & & $102 / 37.4$ & $0.030^{*}$ & $232 / 40.6$ \\
\hline \multicolumn{5}{|l|}{ School absenteeism } & $75 / 13.1$ \\
\hline \multicolumn{6}{|c|}{ Perceived risk factors (n/\%) } \\
\hline Sitting most of the time & & 29/10.6 & $33 / 11.1$ & & $62 / 10.9$ \\
\hline Standing most of the time & & $21 / 7.7$ & $19 / 6.4$ & & $40 / 7.0$ \\
\hline Walking most of the time & & $21 / 7.7$ & $22 / 19.6$ & & $43 / 7.5$ \\
\hline Depression/anger & & $2 / 0.7$ & $7 / 2.3$ & & $9 / 1.6$ \\
\hline Activities requiring bendir & & $44 / 16.7$ & $49 / 16.4$ & & $93 / 16.3$ \\
\hline School bag weight & & $41 / 15.0$ & $39 / 13.1$ & & $80 / 14.0$ \\
\hline Others & & $5 / 1.8$ & $6 / 2.0$ & 0.790 & $11 / 1.9$ \\
\hline \multicolumn{6}{|c|}{ After school activity (n/\%) } \\
\hline Leisure & & $113 / 41.4$ & $82 / 27.5$ & & $195 / 34.2$ \\
\hline Commercial & & $26 / 9.5$ & $39 / 13.1$ & & $65 / 11.4$ \\
\hline Others & & $8 / 2.9$ & $5 / 1.7$ & $0.036^{*}$ & $13 / 2.3$ \\
\hline
\end{tabular}

$*=$ Significant difference at $\alpha=0.05$ (two tailed)

The lifetime, 12-month, one-month and point preva- most perceived risk factor for LBP among participant lence rates among girls were $57.4 \%, 43.6 \%, 26.2 \%$, and $\quad$ was activities requiring bending $(16.7 \%)$ and only $11.4 \%$ $16.2 \%$ respectively compared to $58.6 \%, 44.0 \%, 24.9 \%$ of participants engaged in commercial activities after and $13.2 \%$ respectively among boys. About $41.0 \%$ of school. Significant gender differences were howeve the participants reported recurrence of their LBP and found for recurrence of low back pain and after school $13.1 \%$ had been absent from school due to LBP. The activity. Period prevalence rates according to age groups are presented on Table 3.
Table 3: Period prevalence rates of participants by age group

\begin{tabular}{|c|c|c|c|c|c|c|c|c|}
\hline \multirow[b]{2}{*}{ Age group (years) } & \multicolumn{3}{|c|}{$\begin{array}{l}\text { Boys } \\
(n=273)\end{array}$} & \multicolumn{2}{|c|}{$\begin{array}{l}\text { Girls } \\
(\mathrm{n}=298)\end{array}$} & \multirow{2}{*}{\multicolumn{3}{|c|}{$\begin{array}{c}\text { All } \\
(\mathrm{n}=571)\end{array}$}} \\
\hline & $10-13$ & $14-16$ & $17-19$ & $10-13$ & $14-16$ & $17-19$ & & $17-19$ \\
\hline \multicolumn{9}{|c|}{ Period prevalence (\%) } \\
\hline Lifetime & 55.5 & 60.7 & 60.7 & 48.2 & 60.6 & 70.2 & $51.8 \quad 60.7$ & 64.8 \\
\hline 12-month & 39.1 & 44.1 & 52.5 & 37.7 & 43.1 & 59.6 & $38.4 \quad 43.5$ & 55.6 \\
\hline One-month & 22.7 & 24.5 & 29.5 & 21.9 & 23.4 & 44.7 & $22.3 \quad 23.8$ & 36.1 \\
\hline Point & 6.4 & 15.6 & 21.3 & 14.1 & 13.1 & 27.7 & $10.7 \quad 14.1$ & 24.1 \\
\hline
\end{tabular}

All period prevalence rates increased with increasing alence was higher in girls except in 14-16 years age age while boys had higher lifetime, 12-month and one- group. Association of period prevalence rates with age month prevalence rates until age group 17-19 when the group, sex, history of back injury and engagement in afprevalence was higher in girls. However, point prev- ter-school commercial activities is presented in Table 4.

Table 4: Association of period prevalence rates of adolescent low back pain with age group, sex, history of injury and engagement in commercial activities

\begin{tabular}{|c|c|c|c|c|c|c|c|}
\hline \multirow{3}{*}{ Variable } & \multirow{2}{*}{\multicolumn{2}{|c|}{$\begin{array}{l}\text { PERIOD } \\
\text { Life time }\end{array}$}} & \multicolumn{3}{|c|}{ PREVALENCE } & \multirow{2}{*}{\multicolumn{2}{|c|}{ Point }} \\
\hline & & & $12-\mathrm{m}$ & onth & One-month & & \\
\hline & $\chi^{2}$ & $\mathbf{p}$ & $\chi^{2}$ & $\mathbf{p}$ & $\chi^{2}$ & & $\mathbf{p}$ \\
\hline Age group & 6.31 & $0.043^{*}$ & 8.73 & $0.013^{*}$ & $7.920 .019 *$ & 10.35 & $0.006^{*}$ \\
\hline & 0.09 & 0.767 & 0.03 & 0.872 & $0.12 \quad 0.727$ & 1.00 & 0.317 \\
\hline History of back injury & 12.02 & $20.001 *$ & 7.12 & $0.008^{*}$ & $8.59 \quad 0.003 *$ & 2.92 & 0.087 \\
\hline Engagement in commercial & & & & & & & \\
\hline activities & 8.72 & $0.003 *$ & 6.51 & $0.011^{*}$ & $7.150 .007 *$ & 5.02 & $0.025^{*}$ \\
\hline
\end{tabular}

Age group $(p \leq 0.043)$ and engagement in after-school $=0.003)$ while sex had no significant association $(p \geq$ commercial activities $(\mathrm{p} \leq 0.003)$ were significantly 0.317 ) with any of the period prevalence rates. Period associated with all period prevalence rates, history of prevalence rates of adolescent low back pain from five back injury was significantly associated with lifetime similar studies and a systematic review are presented in $(p=0.001), 12$-month $(p=0.008)$ and one-month $(p \quad$ Table 5 . 
Table 5: Comparison of period prevalence rates on adolescent low back pain from different

studies

PERIOD PREVALENCE (\%)

STUDY
POINT

2-MONTH 1-MONTH

\begin{tabular}{|c|c|c|c|c|c|c|c|}
\hline Our study & 2013 & Nigeria & 571 & 58.0 & 43.8 & 25.6 & 14.7 \\
\hline Ayanniyi et al & 12011 & Nigeria & 1863 & $25.0 \%$ & - & - & - \\
\hline $\begin{array}{l}\text { Onofrio et al } \\
13.7\end{array}$ & 2012 & Brazil & 1233 & - & - & - & \\
\hline Sato et al & 2008 & Japan & 43,630 & 28.8 & - & - & 10.2 \\
\hline $\begin{array}{l}\text { Bejia et al } \\
13.0\end{array}$ & 2005 & Tunisia & 622 & 28.4 & - & - & \\
\hline $\begin{array}{l}\text { Prista et al } \\
\text { Louw et al }\end{array}$ & $\begin{array}{c}2004 \\
2007\end{array}$ & \multirow{2}{*}{\multicolumn{2}{|c|}{ Mozambique 204}} & 28.0 & 13.5 & 12.0 & - \\
\hline (systematic re & view) & & & 36.0 & 33.0 & - & 12.0 \\
\hline (systematic re & view) & & & 39.9 & 33.6 & 18.3 & 12.0 \\
\hline
\end{tabular}

Rates from the present study were higher than those There was no significant association between engagefrom previous studies but followed the same trend. ment in commercial activities after school and age ( $\mathrm{Ta}-$ ble 6).

Table 6: Association between engagement in commercial activities and age

\begin{tabular}{|c|c|c|c|c|}
\hline \multirow[b]{2}{*}{ Age Group (years) } & \multicolumn{2}{|c|}{ Engagement in Commercial Activities } & \multirow{2}{*}{ Pearson $\chi$} & \multirow[t]{2}{*}{$\mathbf{p}$} \\
\hline & Yes & No & & \\
\hline $10-13$ & 24 & 200 & 1.084 & 0.582 \\
\hline 14-16 & 32 & 207 & & \\
\hline $17-19$ & 11 & 97 & & \\
\hline
\end{tabular}

\section{Discussion}

Participants in this study were aged 10 to 19 years which conforms with the WHO's definition of adolescence ${ }^{19}$ and age range of participants in previous studies on adolescent low back pain ${ }^{4.5,6,6,11,12}$ The mean age of partic ipants at first episode of back pain was $11.86 \pm 2.36$ years (range: 5- 18 years).

years in developed countries (i.e. 7 to $70 \%)^{13}$. The poin prevalence from this study was however similar to values from other studies ${ }^{6,12,20}$ and the mean values reported in systematic reviews ${ }^{14,21}$. Two reasons that have been majorly adduced for differences in prevalence rates of ALBP across studies are the definition of low back pain and the study's design. ${ }^{13}$

The lifetime, twelve-month, one-month and point prev- In this study, back pain was defined as pain or discomalence rates of adolescent low back pain were $58.0 \%$, fort felt in the lumbo-sacral region of the back that is $43.8 \%, 25.6 \%$ and $14.7 \%$ respectively. These values not related to menstrual period or feverish illness such though higher than values from most of the previous as common cold or flu. Participants were also assisted studies $4,5,6,8,11,12$ fall within the range reported by Jeffries by a pictorial representation of the reference area. Comet $\mathrm{l}^{13}$ for the prevalence of low back pain during school mon problems in recall prevalence rates are recall decay and forward telescoping. The extent to which participants are affected by these twin factors will determine the accuracy of all recall prevalent rates except point prevalence which will not be subjected to the influence of such factors. It is not surprising therefore that there was less variation in the point prevalence rates from the different studies in comparison to other recall rates as the longer the time period the greater the influence of memory decay. Memory decay is also affected by the significance of the incidence (back pain) and the innate ability of participants to recall events which could have affected participants in the different studies differently. Also, while point prevalence in this study was defined as pain at the time of the study, another study defined point prevalence as pain in the last 30 days $^{12}$ which could have been somehow affected by recall. As reported in previous studies, period and lifetime prevalence rates were higher than point prevalence rates with the rate being higher with longer period of recall ${ }^{14,19,21,22}$.

It is however instructive that the back pain suffered by $85.7 \%$ of participants lasted less than one week and 93.6 $\%$ for less than one month. This is considerably higher than the $66.7 \%$ and $86.1 \%$ for less than one week and less than one month respectively reported by Sato et $a^{16}$. It seems therefore that back pain in majority of the participants can be described as transient and mild.

Although there was no significant association between gender and recall prevalence rates, boys had highe lifetime and twelve-month prevalence rates while girls had higher one-month and point prevalence rates. Our finding is contrary to that of Sato et $\mathrm{a}^{16}$ who reported higher point prevalence among boys and higher lifetime prevalence among girls. However, Onofrio et $\mathrm{al}^{12}$ found higher point prevalence (defined as low back pain in the last 30 days) in girls. Like in this study, Ayanniyi et a ${ }^{11}$ found no significant association between low back pain prevalence and gender. Also, lifetime, twelve-month and one-month prevalence rates for boys were higher for the 10-13 and 14-16 age groups while at age group 17-19, all prevalence rates were higher in girls. Differences in growth rates between boys and girls could have accounted for the observed differences as high growth rate has been identified as a risk factor for the development of low back pain in adolescents.

Age and engagement in commercial activities after school were significantly associated with all period evalence rates while history of back injury was significantly associated with all period prevalence rates except point prevalence. Ayanniyi et $a 1^{11}$ reported significant association between age and prevalence of ad olescent back pain while point and lifetime prevalence rates have been found to increase with age by Sato et $a^{16}$. Indeed, all period prevalence rates increased with increasing age in this study. Our finding of significant association between engagements in commercial activities after school hours agrees with that of Feldman et $a^{13}$ and Ayanniyi et a $1^{11}$.

For economic reasons, a sizeable proportion of adolescent Nigerian students are forced to engage in after-school commercial activities in order to complement the lean family purse. It is therefore not unusual especially in big cities to find such children engaging in street hawking and sometimes acting as bus boys; activities that involve covering long distances by foot while pounding the roads and lifting loads for passengers respectively. Such activities may expose the adolescents to back injuries that may culminate in low back pain. This is especially so since walking more than 30 minutes per day has been found to be associated with an increased risk of low back pain among adolescents in Mozambique $^{22}$.

However, despite the expected interdependence be( the significant associations between the period prevalence rates and engagement in commercial activities after school, there was no significant association between engagement in commercial activities and participants age. This may be because children of varying ages are forced by their parents or guardians to engage in commercial activities before or after school hours. Point prevalence of adolescent low back pain was probably not associated with back injury because such injuries may not be serious enough to cause immediate low back pain but are repetitive in nature. The finding of significant associations between both engagement in after-school commercial activities and previous back injury suggest that both may be contributory or risk factors for the development of low back pain among adolescents.

Activities requiring bending (16.3\%), school bag weight $(14 \%)$ and sitting most of the time $(10.9 \%)$ were the most common perceived risk factors for low back pain 
among participants. This finding is similar to that from Ayanniyi et $\mathrm{al}^{11}$ and Onofrio et $\mathrm{al}^{12}$. The association between both prolonged/repeated bending and prolonged sitting and low back pain among adults are well established in literature hence it is not surprising that both activities have been identified as leading risk factors in this study. However, the link between school bag weight and adolescent low back pain has been anything but univocal. Thus, while Onofrio et $\mathrm{al}^{12}$ found significant association between backpack weight and adolescent low back pain prevalence, neither satchel weight nor the mode of its carriage was found to be associated with adolescent low back pain among Tunisian adolescents $^{20}$. Low back pain was responsible for absence from school $\quad$ C. The Course of Low Back Pain From Adolescence to in 13.1 percent of participants (boys $=11.7 \%$; girls $=$ Adulthood Eight-Year Follow-up of 9600 Twins. Spine $14.4 \%$ ) while $40.6 \%$ (boys $=43.6 \%$; girls $=37.6 \%$ ) of $2006 ; 31(4): 468-472$

participants with low back pain had recurrent pain. Ab- 3. Feldman D E, Shrier I, Rossignol M, and Abenhaim senteeism resulting from low back pain in this study was L. Risk Factors for the Development of Low Back Pain lower than the 23\% recorded among Tunisian school in Adolescence. American Journal of Epidemiology 2001; children ${ }^{20}$ and the recurrence rate lower than the 60.5\% $154(1): 30-36$

among school children in Japan. The higher recurrence 4. Pellise F., Balague' F., Rajmil L., Cedraschi C., Aguand lower absenteeism among boys may suggest that irre M., Fontecha C. G., Pasar1'n Maribel, Ferrer Montboys may be going to school despite their pain thus se. Prevalence of Low Back Pain and Its Effect on not allowing for complete or adequate recovery and Health-Related Quality of Life in Adolescents. Archives thereby increasing the chances of recurrence. Absence of Pediatrics \& Adolescent Medicine 2009; 163(1): 65 from school among adolescents cannot however be ex- 71 .

plained exclusively by low back pain as there are other 5. Olsen T L, Andetson R L, Deanwate S R, Andrea likely reasons that were not considered in this study and M. K, Jane A. Cauley, Deborah, J. Aaron, and Ronald truancy is quite common among students of this age E. LaPorte. The Epidemiology of Low Back Pain in an category. For instance, it is likely that back pain merely Adolescent Population. American Journal of Public Health served as a good excuse for some of the participants to 1992; 82(4): 606-608.

be absent from school while pain culture in the family 6. Sato T., Ito T, Hirano T., Morita O., Kikuchi R., and peer influence might have influenced the response of some to back pain.

Limitations: A major limitation to this study is its cross-sectional nature which does not permit cause and effect interpretation of its findings. Indeed, aetiology of adolescent low back pain was not investigated in this study. Also worthy of note are the usual limitations associated with recall prevalence studies- memory decay and forward telescoping. Finally, other variables beside low back pain that may precipitate school absenteeism among adolescents were not considered in this study. Conclusions from this study should hence be drawn cautiously. Endo N., Tanabe N. Low back pain in childhood and adolescence: a cross-sectional study in Niigata City. Eu ropean Spine Journal 2008; 17: 1441-1447.

7. Jones M. A., Stratton G., Reilly T. and Unnithan V. B. 7.ological risk indicators for recurrent non-specific low back pain in adolescents. British Journal of Sports Medicine 2005; 39: 137-140.

8. Jones M. A., Stratton G., Reilly T. and Unnithan V. B. A school-based survey of recurrent non-specific lowback pain prevalence and consequences in children. Health Education Research; Theory \& Practice 2004; 19(3): 284-289.

9. Boćkowski L, Sobaniec W, Kułak W, Śmigielska-Kuzia J, Sendrowski K, Roszkowska M. Low back pain in diagnostic management. Advances in Medical Sciences 2007; 52(1): 221-223. lor S, Symmons D P M, Silman A J, Macfarlane G J. Low back pain in schoolchildren: the role of mechanical and psychosocial factors Archives of Diseases of Children 2003; 88: 12-17.

11. Ayanniyi O, Mbada C E, Muolokwu C A. Prevalence and Profile of Back Pain in Nigerian Adolescents. Medical Principles and Practice 2011; 20(4): 368-373.

12. Onofrio A C, da Silva M C, Domingues M R, Rombaldi A J. Acute low back pain in high school adolescents in Southern Brazil: prevalence and associated factors. European Spine Journal 2012; 21(7): 1234-40.

13. Jeffries L J, Milanese F S, Grimmer-Somers K A. Epidemiology of Adolescent Spinal Pain: A Systematic Overview of the Research Literature. Spine 2007; 32(23): 2630-2637.

14. Louw Q A, Morris L D, Grimmer-Somers K. The Prevalence of low back pain in Africa: a systematic review BMC Musculoskeletal Disorders 2007; 105(8).

15. Kasiulevičius V., Šapoka V, Filipavičiūtè R. Sample size calculation in epidemiological studies. Gerontologia. 2006; 7(4): 225-231.

16. Kuorinka I, Jonsson B, Kilbom A, Vinterberg H, Journal. 2004; 13: 341-345. 18(3):233-237 (7451): 1312-1315 $2 / 08 / 12$. 25(5):715-720.
Biering-Sørensen F, Andersson G, Jørgensen K. Standardized Nordic questionnaires for the analysis of mus-

17. Nyland L. J. and Grimmer K. A. Is undergraduate physiotherapy study a risk factor for low back pain? A prevalence study of LBP in physiotherapy students. BMC Musculoskeletal Disorders 2003; 4(22):1471-1474.

18. Boynton P M and Greenhalgh T. Hands-on guide to questionnaire research; Selecting, designing, and deeloping your questionnaire. British Medical Journal 2004;

1VHO (2012): Adolescent health http://www. who.int/topics/adolescent_health/en/ accessed on

20. Bejia I, Abid N, BenSalem K, Touzi M and Bergaoui in in Tunisian adolescents. Clinical Rheumatology. 2005;

21. Calvo-Munoz I, Gomez-Conesa A, Sanchez-Meca J: Prevalence of low back pain in children and adolescents. a meta-analysis. BMC Pediatrics 2013; 13:14 22. Prista A, Balague F, Nordim M, Skovron ML. Low school-age children: risk factors, clinical features and 